\title{
Malignant Testicular Neoplasm
}

National Cancer Institute

\section{Source}

National Cancer Institute. Malignant Testicular Neoplasm. NCI Thesaurus. Code C7251.

A primary or metastatic malignant neoplasm that affects the testis. Representative examples include seminoma, embryonal carcinoma, sarcoma, leukemia, and lymphoma. 